\title{
BEYOND DOMINANCE: THE IMPORTANCE OF LEVERAGE
}

\author{
Rebecca J. Lewis \\ Biological Anthropology and Anatomy, Duke University \\ Durham, North Carolina 27708 USA \\ E-MAIL: RJL6@DUKE.EDU \\ KEYWORDS
}

power, dominance, leverage, relationships, biological markets, resource holding potential, submissive signals

\begin{abstract}
The dominance concept as it is currently defined and applied in animal behavior is problematic. What has been traditionally considered dominance is actually a combination of dominance in the strict sense and power based upon other sources. Rather than working within the current paradigm, I propose a conceptual revision founded upon the more inclusive concept of power. Power is a phenomenon where a dyadic relationship is asymmetrical (Simon 1953) and can be divided into two types: dominance and leverage. Dominance is power based upon the ability to use force. Leverage is power based upon a resource that cannot be taken by force. Four characteristics of power are used in sociology (base, means, amount, and scope) that facilitate both the expansion of the power concept beyond traditional dominance and the application of these theoretical ideas in empirical studies. This crossdisciplinary approach to power allows a wide range of behaviors to be considered as critical while at the same time it focuses the attention of researchers to the aspects of power that differ among dyads, classes, and species. Power is not simply a linear combination of dominance and leverage, and more research is needed before the exact nature of this relationship can be clarified. By considering dominance as one form of power, this framework fosters a more complete understanding of power dynamics and their effects on animal societies.
\end{abstract}

\section{$\mathrm{C}$} ONFUSION AND CONTROVERSY have surrounded the concept of dominance almost since it was introduced by Thorleif Schjelderup-Ebbe in 1922. Various authors (e.g., Bernstein 1981; de Waal 1986; Hand 1986; Drews 1993; Piper 1997) have attempted to clarify the dominance concept in hopes of creating consistency in how it is applied, but the confusion persists. In particular, interspecific comparisons have been complicated by the lack of a single definition for dominance (cf. Drews 1993). This problem has only been magnified with researchers us- ing different methods for applying the concept of dominance to empirical studies (e.g., direction of aggression: Vestergaard et al. 1993; priority of access: Lemel and Wallin 1993; direction of aggression and priority of access: Frank 1986; spatial position and priority of access: Johnsson 1993; weight: Dugatkin and Ohlsen 1990). Consequently, attempts to link dominance and fitness have met with mixed results, causing the evolutionary significance of the dominance concept itself to be called into question (for review: Fedigan 1983). 


\section{Power}

I propose a more inclusive framework for analyzing social relationships based upon the concept of power. Power, as derived from political science, economics, and sociology (where it has been explicitly studied for decades), more accurately describes asymmetries in relationships between individuals than the narrowly defined traditional concept of dominance. Power is a phenomenon where a dyadic relationship is asymmetrical (Simon 1953). The asymmetry in the dyad may be related to resource holding potential (RHP: Maynard Smith and Parker 1976; also called fighting ability: Hand 1986; Noë 1990; Hamilton and McNutt 1997), but it can also be based upon the fighting ability of coalition partners (de Waal 1996), the possession of an inalienable commodity (Noë et al. 1991), an asymmetry of knowledge (Hand 1986), or even an asymmetry in "dependence" (Emerson 1962). Simon's (1953) definition of power is advantageous because it disconnects power from aggression. While Simon is correct in asserting that $A$ has power over $B$ if an asymmetry exists in this direction (regardless of whether $A$ takes advantage of it), some biologists contend that the asymmetry is only of interest when preferences conflict (Hand 1986; Noë et al. 1991), specifically in contest competition (Preuschoft and van Schaik 2000). Accordingly, Simon's definition of power will be used in this paper with the assumption that asymmetries will only be expressed when preferences conflict.

\section{DOMINANGE AND LEVERAGE}

Power is a more inclusive concept because it comprises both dominance and leverage. In this framework, dominance is defined as power based upon force or the threat of force (cf. "competitive ability": de Waal 1989). This definition is consistent with much of the previous research because dominance has traditionally been associated with fighting ability (Packer and Pusey 1985; Chapais 1991; Pierotti et al. 1997). The close relationship between dominance and fighting ability accounts for the fact that dominance is often correlated with body size (Dugatkin and Ohlsen 1990; Lemel and Wallin 1993; Piper 1997). Also note that dominance does not require the use of force but can also be based upon the potential to use force, for even the infrequent use of force can be very effective (Chapais 1992). Following Hand (1986), two types of dominance can be distinguished: (1) intrinsic dominance, based upon an individual's own ability to use force; and (2) derived dominance, based upon fighting ability that is not physically associated with that individual, such as coalition and alliance partners. Thus, bridging alliances, revolutionary alliances, and dependent rank are all examples of derived dominance (Chapais 1992).

Power can also be based upon resources that cannot be taken by force; that is, resourcebased power or leverage (Hand 1986; Smuts 1987; Noë 1990; Noë et al. 1991; de Waal 1996). Leverage is thus defined as power based upon inalienable resources, and can arise from any number of asymmetries. Examples of resources that cannot be taken by force, which form the basis for leverage, include fertilizable eggs (Hand 1986), skills (Hand 1986), services (e.g., grooming: de Waal 1989), or even genes, as in kinship and inclusive fitness (Hand 1986; de Waal 1996). An individual may have leverage due to demographic variables, such as population sex ratios (Emlen and Oring 1977), where "market effects" are likely to be observed (Noë et al. 1991); indeed, mate choice (or the power to choose a preferred mate) may be derived from these demographic variables (for discussion of power and mate choice: Bergstrom and Real 2000). An individual may also have leverage during acts of cooperation due to the collective action problem (e.g., by the threat of free-riding: Nunn and Lewis 2001), or by the threat of terminating the collaborative effort (de Waal 1996)-for example, by being less "dependent" upon the collaboration (power-dependency theory: Emerson 1962).

While a coalition partner, $C$, can conceivably be argued to be a source of leverage for $B$ in the dyad $A a n d B$, coalition partners in the power framework are considered to be derived dominance consistent with Hand (1986). For clarity, any source of power relating to force is included with dominance. The coalition partner, $C$, however, does have leverage in its relationship with $B($ dyad $B a n d C)$ because it 
is providing a service that $B$ relies on in $B$ 's relationship with $A$. For instance, in Chimpanzee Politics, de Waal (1982) reports a series of takeovers in a colony of common chimpanzees (Pan troglodytes). The situation involved three adult males: Luit, Nikkie, and Yeroen. At one point Luit was the alpha male, Nikkie was the beta male, and Yeroen had recently fallen to the gamma position. Nikkie then formed a coalition with Yeroen to overthrow Luit. Nikkie's takeover would not have been successful without Yeroen's support, thus Nikkie had superior derived dominance in his relationship with Luit due to his coalition with Yeroen (Figure 1a). As a coalition partner, Yeroen provided additional force for Nikkie and was therefore a source of dominance for Nikkie; however, Nikkie needed Yeroen to maintain his position over Luit, thus Yeroen had leverage in his relationship with Nikkie because of Nikkie's dependence on the NikkieYeroen coalition (Figure 1b). Coalitionary support is not a resource or service that can be taken by force, and thus was a source of leverage for Yeroen. In fact, Yeroen did receive special benefits due to Nikkie's dependence on him: Yeroen was able to mate approximately twice as often as Nikkie in Nikkie's first year as alpha male, though when Nikkie was no longer as dependent upon Yeroen to maintain his status, the situation was reversed and Nikkie mated more than twice as often as Yeroen.

\section{Examples of Leverage: Reinterpreting Data}

Numerous examples may be found in previous research in which the concept of power more precisely describes changes in dyadic relationships that dominance alone was unable to explain. For example, females in estrus often experience an advantageous change in social relationships without changing positions in the dominance hierarchy (Carpenter 1942; Hall and De Vore 1965; Datta 1983; de Waal 1986). This change has puzzled researchers because it does not fall in line with current theories about dominance. De Waal (1986) attempted to alleviate this and similar problems by distinguishing between two layers of dominance: formal dominance, which is stable, and real dominance, which is flexible. While this distinction is useful for identifying differences in power, rec- a)
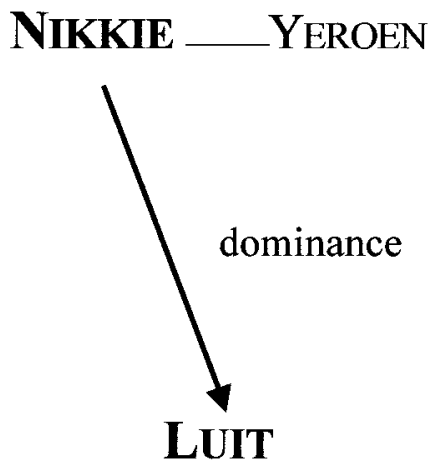

b)
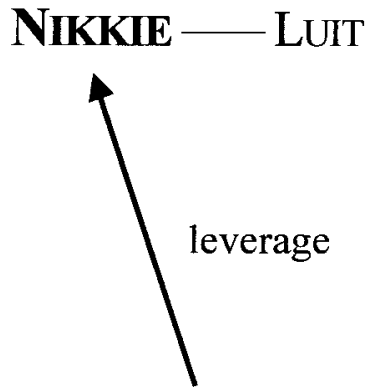

\section{YEROEN}

Figure 1. An Example of Derived Dominance ANd Leverage in CoAlitions.

Coalitions create a situation in which both dominance and leverage may occur. a) Nikkie has dominance in his relationship with Luit as a result of his coalition with Yeroen. b) Yeroen has leverage in his relationship with Nikkie because Nikkie depends upon him for a coalition against Luit.

ognizing layers of dominance does not always clarify the dominance concept and leaves vital questions unanswered. For instance, when is an observed behavior formal dominance versus real dominance? What is the basis for the difference? Are higher cognitive abilities required for formal dominance (cf. Maestripieri 1996)? As de Waal (1986) stated himself, adopting this new terminology is constructive but cannot fully explain the phenomena. 
By placing this observation of temporary changes in the status of estrus females within the broader framework of power, the puzzle disappears. As long as the female's ability to achieve outcomes through force does not change, her dominance does not change. Rather, the female rises to an advantageous position because her leverage changes. She has an inalienable commodity: her egg that is ready to be fertilized. When the female is no longer in estrus (i.e., when that egg is no longer available), the female's leverage decreases. Thus, temporary fluctuations in power are inevitable and predictable. Signaling, which is used to differentiate between de Waal's formal and real dominance, is shifted in this new framework from defining dominance styles to a characteristic of power (see below), where precise interindividual and interspecific comparisons can be made. Moreover, complex cognitive abilities are not required for leverage to occur (for debate about cognition and formal dominance: Maestripieri 1996; Preuschoft 1999). Rather, individuals only need to be able to perceive an asymmetry in the dyad.

The usefulness of the power concept is also evident in studies in which cognition plays a role. For example, Stammbach (1988) trained a long-tailed macaque (Macaca fascicularis) group to use a simple lever machine to obtain food. The operation was then made more complex and only a single subordinate individual was trained to complete the task. Once the task was completed, however, other group members were able to feed at the dispenser. Although the knowledgeable subordinate did not rise in dominance rank, he received significantly more grooming than before the training. According to the traditional definitions of dominance, training the subordinate did not increase his social power. With the broader concept of power, however, the explanation is obvious: the subordinate increased his leverage with his differential increase in knowledge. A skill or knowledge can be a source of leverage (Hand 1986; Noë 1990) as long as it is a scarce commodity. This commodity can be exchanged for other commodities or services, such as grooming.

Leverage can be viewed as economic power while dominance is more physical in nature.
These two types of power exist along a continuum, but I will focus on the extreme forms for clarity (for a discussion of leverage in terms of a cost to benefit ratio, "winning inappropriately," see Hand 1986).

\section{POWER AS A GENERAL TERM}

The term "power" is not new to animal behavior, despite the fact that dominance is used to explain most of the phenomena that relate to power in animal societies. "Dominance" and "power" have even been used interchangeably in the animal behavior literature (e.g., de Waal 1982; Datta 1983, 1989; Chapais 1992). This historical interchange of dominance and power comes from the fact that authors have referred to dominance in different ways: dominance sensu stricto, which is what I refer to as "dominance" in this framework, and dominance sensu lato, which is what I refer to as "power." Moreover, "power" is often used in the animal literature without the author providing a definition (e.g., de Waal 1982, 1986; Datta 1983; Smuts 1985; Noë 1992; Gowaty 1997; Vervaecke et al. 2000), yet when power is defined, the definitions are neither consistent nor are they always analogous to dominance. It is important for the two terms "dominance" and "power" to remain distinct. According to the framework introduced in this paper, power is the more general term and may refer to either dominance or leverage (Figure 2). Moreover, in this framework, power only refers to dyadic relationships ( sensu Hinde and Stevenson-Hinde 1976). Perhaps some polyadic "power" phenomena do exist (Jessica Flack, personal communication), such as "respect," "prestige" (Barkow 1975), or "referent power" (cf. Jones 2000). "Power" that goes beyond the dyadic level is probably rare outside of humans, however. In addition, even polyadic "power" can still be analyzed at the dyadic level with the framework provided, assuming an asymmetry in this polyadic "power" exists in a dyad (see also powerdependency and exchange networks: Cook and Emerson 1978; Cook et al. 1983).

\section{PROXIMATE CHARACTERISTICS OF POWER}

Power has certain characteristics that can be used as a basis for measure and comparison (see also Chapais 1991). Various social sci- 


\section{POWER}

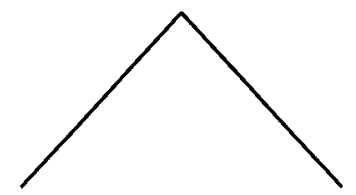

DOMINANCE

(coercion potential)

(fighting ability)

(competitive ability)

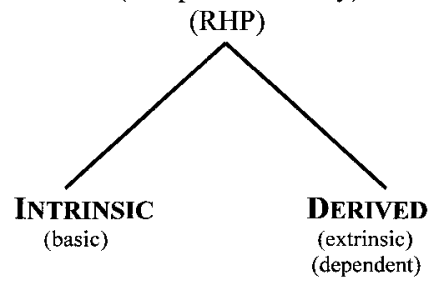

Figure 2. Diagram of Power and Its Components.

Power is a phenomenon where an asymmetry exists in a dyadic relationship and can be divided into 2 types: Dominance and Leverage. Dominance can then be further divided into Intrinsic and Derived.

entists have put forth their own version of the list of important qualities of power. Dahl (1957), however, provides a set of four characteristics that seem most useful for the analysis of animal behavior: base, means, amount, and scope. Base refers to the source of power, such as fighting ability or control over mating opportunities. Means refers to the instruments of power, such as a threat or a reward, and is the way the relationship is negotiated. Amount refers to the magnitude of power over a number of categories (cf. "spheres of dominance": Hand 1986); in other words, amount addresses the question of whether power varies with the context. Scope is the range of power, and consists of $B$ 's responses to $A$ (i.e., the behaviors that $A$ is able to evoke in $B$ ). Thus, base, means, amount, and scope are ways to measure why, how, when, and to what extent power occurs. These proximate characteristics allow biologists to operationalize power, connecting the theoretical construct to the day-to-day behaviors that researchers measure. Moreover, these characteristics also permit researchers to move away from simply using outcomes to define power.

For example, suppose that a male baboon has power over another male baboon. His power is based upon his greater fighting ability (i.e., dominance). He can enforce his power by means of a yawn, a threat that demonstrates the size of his weapons (i.e., his canines). The amount of his power over the other male could be an $85 \%$ probability of winning contested food and sleep sites, but only a $55 \%$ probability of winning contests over receptive females. The scope of his power includes the ability to evoke the entire repertoire of submissive behaviors from the other male. At the same time, this powerful male may experience a different relationship with a female of his species. While the male has a greater fighting ability than the female, she may have greater power based upon her egg that is ready to be fertilized (i.e., leverage). She can enforce this power by means of refusal to copulate with that male (i.e., withholding a reward). The amount of her power may indeed vary with her reproductive state, and the scope of her power may include the ability to elicit grooming and coalitionary support.

These proximate characteristics are critical to revising concepts of power in nonhumans. The term "base" highlights why power occurs and allows for nondominance powers to be considered as relevant. "Means" implies more than just aggression; both agonistic and affiliative behaviors may be used to negotiate power. "Amount" not only addresses the issue of the context-dependency of power, but because it is expressed as a probability, it also indicates how often the power occurs. Finally, "scope" will often refer to (but is not limited to) submissive behaviors: an individual may have the power to evoke physiological responses such as musth suppression (African elephants: Poole 1989). Scope can also include services such as grooming, vigilance, or coalitionary support. These characteristics facilitate the expansion of the concept of power beyond traditional dominance in nonhumans, while at the same time allowing for the application of these ideas in empirical studies.

\section{Clarifying Dominance with the Concept of Power}

While various researchers have attempted to break free of the narrow paradigm that power is limited to dominance (e.g., Noë et 
al. 1980; Hand 1986; Chapais 1991; Noë et al. 1991; Gowaty 1997), these insights have yet to be incorporated into studies of social behavior in animals. Dominance has been useful for explaining a good portion of power relations in animal societies because it is a relatively easy basis for an individual with greater fighting ability to achieve its preferred outcomes. Nevertheless, other strategies for achieving preferred outcomes are available. The concept of power allows a wide range of behaviors to be considered as critical while at the same time focusing the attention of researchers on the aspects of behavior that differ among dyads, classes, and species. This broader concept of power reduces the confusion historically associated with traditional dominance.

First, the definition of dominance is simplified within the framework of power. Dominance refers to a phenomenon where an individual's preferences take precedence in a dyadic relationship because of an asymmetry in fighting ability. The ability to use force can be gauged with measures such as body size, weapon size, and number and strength of coalition partners. Only when the power dynamic is based upon force or the threat of force can it be called dominance. If the power base is uncertain, the more general term "power" is preferable.

Second, this clear definition of dominance delineates clear applications. Dominance, like all forms of power, is dyadic. Sometimes "male dominance" or "female dominance" is used to refer to the power of one class of individuals relative to another class of individuals. These terms are useful as shorthand for a general phenomenon as long as the measures and implications remain dyadic. Female dominance, in particular, has stirred a heated debate in the primate literature. Some primatologists follow a classic ethological approach by defining dominance in terms of the outcomes of agonistic encounters (e.g., Pereira et al. 1990). Others (e.g., Jolly 1984) contend that female dominance is essentially different from male dominance because it concerns priority of access to resources. Within the framework of power, however, female dominance over males occurs only when female fighting ability is su- perior to males in intersexual dyadic interactions. Species in which males and females have equal abilities to use force may exhibit female priority of access to resources based upon economic power; these species exhibit female leverage, not female dominance. Moreover, when power structures are not sex dependent, such as in the monomorphic brown hyena, Hyaena brunnea (Owens and Owens 1996), shorthand terms such as female dominance are not constructive and should be avoided. These cases demonstrate that the dyadic analysis of power dynamics has more utility than analysis of sex classes.

Finally, nonaggressive behaviors that may influence power relations are often ignored within the traditional dominance framework (Hand 1986). By defining dominance in terms of the ability to use force, the connection between power and aggressiveness is severed. This disconnection will allow for more accurate descriptions of power structures. Aggression and power may be associated because aggression is one manifestation of power (cf. means) but not because aggression levels determine power (Francis 1988).

The concept of power improves upon the traditional concept of dominance by placing it in a more complete framework. Leverage has been a missing component. Not only is power more inclusive than dominance, but it can also be broken down into four aspects that can be used to more accurately understand the nature of dyadic relationships.

Some zoologists have argued that traditional dominance is context-dependent (e.g., Popp and De Vore 1979; Hand 1986; Francis 1988; Verbeek et al. 1999), while others have claimed that in order for dominance to be a useful concept it must be independent of context (e.g., Bernstein 1981). An individual's power may vary in the dyad, however, due to age, hormonal status, or even population demographics. In many cases, leverage may be context specific while dominance is independent of context and may be relatively constant. Amount (sensu Dahl 1957) is a characteristic of power that can be used to ascertain context dependency. The amount of power that an individual has in a relationship can be determined by calculating the probability of "winning" a contest in different situ- 
ations. This information can be further subdivided into the amount of dominance and amount of leverage (i.e., with different bases), or into the amount of power needed to evoke different submissive signals, physiological responses, or mating opportunities (i.e., scope).

The framework presented here is also useful for analyzing "site-dependent dominance," a term common in, but not limited to, the avian literature (for review: Oberski and Wilson 1991; Piper 1997). What has been traditionally called "site-dependent dominance" refers to the ability of some individuals to win more conflicts in areas that are familiar to them. For example, J L Brown (1963) found that a Stellar's jay (Cyanocitta stelleri) wins encounters when it forages in its nesting area but that social status declines with distance from that nesting area. In other words, a bird has a greater amount of power within its territory but as it moves away from its territory, its power is gradually reduced. Because the ability to use force is not likely to change with the location of the dyad, in most cases dominance probably remains constant across different sites. Knowledge of the area is one variable that does change with location, however, and knowledge can be a source of leverage (Hand 1986). Accordingly, some cases of "site-dependent dominance" may be more appropriately labeled "site-dependent leverage"; for example, if the relationship is based upon knowledge and this leverage varies in amount depending on the location of the dyad (see also the less extreme form of leverage, "winning inappropriately": Hand 1986). As discussed above, by measuring both the amount of power (context) and the base of power (source), investigators can more precisely examine and compare the nature of dyadic relationships when they are evaluated within the framework presented here. It is also important to note that by definition power terms such as "site-dependent dominance" and "sitedependent leverage" refer to relationships and not to interactions (see below).

Variation in power may influence fitness because it is ultimately related to access to resources. By only examining the relationship of dominance to reproductive success (e.g., Dewsbury 1981; Huck et al. 1988; de Ruiter and van Hooff 1993; Inoue et al. 1993; Schartl et al. 1993; Lambert et al. 1994; Holekamp et al. 1997; Pusey et al. 1997; Bartos and Perner 1998; Takahata et al. 1999; van Noordwijk and van Schaik 1999), a study may be incomplete. The influence of rank on reproductive success is more complex than predicted by aggression-based models (Berard 1999). The variable results of these studies may be the consequence of too narrow a definition of the powerful individual. Power structures are more than just dominance hierarchies and should be examined as such.

It is important to keep in mind that dominance and leverage themselves cannot evolve (Rowell 1974; Bernstein 1981). Both dominance and leverage refer to a relationship (e.g., Bernstein 1981; Hand 1986; van Hooff and Wensing 1987; Dewsbury 1990; Drews 1993) rather than an individual (e.g., Maslow 1940), and natural selection cannot act directly on a relationship. Natural selection can, however, act upon the tools that may improve an individual's position in a relationship (e.g., body size or intelligence: Bernstein 1981).

Another important aspect of power that is often confused in cross-species comparisons is that asymmetries may differ between dyads composed of strangers and dyads in which an established relationship exists (Lemel and Wallin 1993; Preuschoft and van Schaik 2000). When two individuals have never met before or both individuals do not recognize each other, a relationship does not exist (cf. Hinde and Stevenson-Hinde 1976) and the terms "power," "dominance," and "leverage" are not appropriate (see also Hand 1986). Power arises out of a dyadic relationship (cf. Simon 1953). Interactions between strangers may be influenced by asymmetries; these interactions should be referred to by other terms that indicate the basis of the asymmetry, however (e.g., size, experience, fighting ability). Strangers are likely to use signals to assess these asymmetries (Lemel and Wallin 1993; Preuschoft and van Schaik 2000) because they do not have an established relationship.

Only when two individuals recognize that they have had repeated interactions with one another can a relationship arise (Hinde and Stevenson-Hinde 1976). Power becomes an important factor in the way two individuals 
with established relationships interact. Distinguishing between dyads of familiars and strangers may therefore be critically important (Preuschoft and van Schaik 2000).

Individuals with established relationships may also use signals to communicate asymmetries. Primatologists have noted that some primates, such as macaques and chimpanzees, exchange signals between dominants and subordinates. These formalized status signals are unidirectional and consistent across context and time (de Waal 1986). As mentioned above, de Waal (1986) created a double-tier hierarchy within the traditional concept of dominance based upon the observation that these formalized status signals do not always agree with priority of access to resources. He suggested that formal dominance is stable and is evident in the unidirectionality of the formal dominance signals. These signals, he asserted, act as a confirmation of the established social relationship. Real dominance does not involve these formal exchanges and permits flexibility across time and context. De Waal recognized how constricted and problematic the traditional dominance definition was and attempted to alleviate these problems. By working within the dominance paradigm, he highlighted the differences between types of power and helped pave the way for the framework presented in this paper.

Power includes both de Waal's (1986) formal and real dominance. His two types of dominance refer to scope (sensu Dahl 1957). An individual that has the power to evoke formalized status signals has a different scope of power than an individual that never receives a formal signal. Moreover, de Waal's real dominance is a combination of leverage and derived dominance (although some derived dominance can reach the level of de Waal's formal dominance).

The issue of relationships is also important when considering power and motivation (defined here as an asymmetry in need). Hunger and other physiological states have been shown to influence the outcomes of animal contests (musth in African elephants: Poole 1989; hunger in great tits: Lemel and Wallin 1993). Not all physiological states are sources of power, however. Hunger is not a desirable resource even though it cannot be taken by force. Estrus, on the other hand, can be a source of power because the female has something that a male wants: a fertilizable egg is a desirable resource for males. Physiological states such as hunger determine the willingness of an individual to escalate the conflict, and thus do have an impact on a particular interaction. In fact, together dominance, leverage, and motivation determine the outcome of competition (cf. de Waal 1989). Nevertheless, while this type of motivation can influence the outcome of a conflict, it does not influence the dyadic relationship per se.

For instance, imagine two male spotted hyenas arriving at a small carcass at approximately the same time. Hyena $A$ has superior fighting ability to hyena $B$, and thus $A$ ultimately has the power to keep $B$ away from the carcass. Further suppose, however, that hyena $A$ has eaten recently and that hyena $B$ is much hungrier. In this instance, hyena $A$ still wants the newly found food, but it prefers to avoid a major contest and find another food source later. Hyena $B$, on the other hand, would prefer to fight for the carcass rather than hunt for food elsewhere, and is thus more willing to escalate the contest. The key difference between the behavior of the two hyenas lies more in the persistence and escalation of the hungry hyena than in the bases of power which determine their long-term dyadic relationship. This example illustrates the point that a contest is only interesting in terms of power dynamics if animals truly have conflicting preferences. While both hyenas would eat the food if it were uncontested, they do not actually have conflicting preferences because one is motivated by intense hunger and the other is not (for discussion of motivation and conflicting priorities in conflicts: Hand 1986). Motivation, as described above, may influence the outcomes of occasional encounters, but it does not influence relationships. Amount (sensu Dahl 1957) is the characteristic of power that measures the probability of winning a contested resource. Over time, any transient motivational differences are unlikely to change the relative amount of power in a relationship.

Motivational asymmetries can be used to influence relationships when motivation is explicitly related to dependency on exchange (see power-dependence theory: Em- 
erson 1962). When an animal controlling a resource that is needed by another exploits that need in order to gain access to some other resource, then the asymmetry in need acts as a source of leverage. For example, suppose that a male lion has superior fighting ability and can keep another hungrier male lion away from a carcass, but the dominant male perhaps needs some assistance in taking over a pride of female lions. If the dominant male uses the hungry lion's greater need for food as a basis of exchange, then the exchange constitutes more than a simple interaction. While the relationship may have started as a result of an asymmetry during an interaction, the system of exchange that was established influences the dyadic relationship: one lion needs food, the other lion needs assistance, and the exchange may continue until the needs of both are satisfied. Thus, motivation can only be used as a source of leverage if the dependency is linked with exchange (i.e., it is used as economic power).

While power is often easy to recognize, operationalizing power is not as simple. The use of different methods for measuring power has exacerbated the problem of multiple definitions. While definitions such as priority of access to resources demonstrate that a power relationship exists, they do not provide any information on why that power relationship exists. The definition of power as an asymmetrical dyadic relationship is sufficient; power must be measured and analyzed by its characteristics.

\section{Application: Power Matrices}

Much of the previous research on dominance is directly transferable into the power framework. Past studies of dominance have actually tested certain aspects of power. For instance, any research that has studied priority of access to food (e.g., Terrill 1987) or water (e.g., Roeder and Fornasieri 1995) has demonstrated which individuals have power in the feeding context. Amount of power can be further elucidated by determining the probability of getting a preferred food item. Hierarchies that are based upon the priority of access to food can then be compared with hierarchies based upon the priority of access to other resources, such as females, nests, or burrows. In addition to determining amount of power, the matrix method can also be used to examine the means of power, such as aggressive behaviors (e.g., spotted hyenas: Jenks et al. 1995), and the scope of power, such as submissive behaviors (e.g., wolves: van Hooff and Wensing 1987) or retreats (dark-eyed juncos: Yasukawa and Bick 1983).

The key difference between previous studies of dominance and the power framework presented here is that the limitations of these individual matrices are acknowledged. No one matrix or hierarchy portrays the complete picture; a combination of matrices provides a skeletal description of the total power structure, however, allowing researchers to determine what behaviors in which contexts have a certain probability of evoking specific responses in other individuals. The researcher must delve deeper to determine the base of power. Estimates of the relative abilities to use force are needed, including body size, body condition, and number of coalition partners.

For example, Vervaecke et al. (1999) conducted experiments to evaluate the consistency of competitive abilities and (traditional) dominance in captive bonobos (Pan paniscus). They assigned (traditional) dominance ranks based on asymmetrical submissive behaviors in dyads. The age and weight data that they provide can be used to roughly estimate relative fighting abilities, and hence, intrinsic dominance. The differences between their dyadic and triadic tests can then be used to estimate extrinsic dominance, creating a fairly complete picture of the dominance structure of this group of bonobos (Table 1).

Vervaecke and colleagues (1999) present a matrix of frequencies of fleeing and peering (submissive behaviors) during competitive feeding bouts (Table 1) that can be used to measure scope (responses that can be evoked). Because this matrix only contains data obtained when animals give or receive aggressive behavior, the matrix can also be used to examine one means of power (i.e., the effectiveness of aggression as an instrument of power). In addition, this very same matrix presents the data in terms of frequencies. Therefore, the amount of power can also be 
TABLE 1

Total frequencies of fleeing upon aggression and peering in the dyadic tests

\begin{tabular}{|c|c|c|c|c|c|c|}
\hline \multirow[b]{2}{*}{ Actor } & \multicolumn{6}{|c|}{ Receiver } \\
\hline & Dzeeta & Hermien & Desmond & Kidogo & Hortense & Ludwig \\
\hline Dzeeta & - & 0 & 0 & 0 & 0 & 0 \\
\hline Hermien & $2(2,0)$ & - & 0 & 0 & 0 & 0 \\
\hline Desmond & $3(1,2)$ & $2(2,0)$ & - & 0 & 0 & 0 \\
\hline Kidogo & $15(15,0)$ & $10(5,5)$ & $1(1,0)$ & - & 0 & 0 \\
\hline Hortense & $2(1,1)$ & $4(4,0)$ & $9(9,0)$ & $3(3,0)$ & - & 0 \\
\hline Ludwig & $37(36,1)$ & $1(1,0)$ & $1(1,0)$ & $1(0,1)$ & $4(3,1)$ & - \\
\hline
\end{tabular}

Individuals in order of their dyadic competitive feeding rank. Actors are the individuals fleeing or peering, while receivers are the other individuals in the dyad. Sum of peering and fleeing upon an aggression. In parentheses: first frequency of peering, then frequency of fleeing upon an aggression. The above table is from Vervaecke et al. (1999).

analyzed. The amount of power refers to the percentage of time that an individual "wins" a conflict in a particular context, in this case, feeding.

Thus, for example, Dzeeta has $100 \%$ probability of evoking peering and fleeing (scope) from Desmond with aggression (means) in the feeding context (amount); Dzeeta is twice as likely to receive a flee than a peer in this situation, however (amount and scope). In contrast, Dzeeta was never seen to receive a flee from Kidogo in the same context, despite evoking five times as much submissive behavior from Kidogo. Hence, Dzeeta has a greater scope of power with Desmond than with Kidogo when she uses aggression in the feeding context.

The base of Dzeeta's power is difficult to resolve from the information provided in the article, though Vervaecke and colleagues do present some clues. First, Dzeeta was 22 years old and weighed $50 \mathrm{~kg}$ at the time of the study, while Desmond and Kidogo were recorded to be 23 years and $58 \mathrm{~kg}$ and 10 years and $42 \mathrm{~kg}$, respectively. This information suggests that, while it may have been a basis for Dzeeta's power with Kidogo (see also Vervaecke et al. 2000), dominance does not fully explain Dzeeta's relationship with Desmond. Second, Dzeeta is a female while Desmond and Kidogo are males. The potential leverage effects based upon Dzeeta's reproductive state are unclear because the authors of the study spread the tests over different phases of the females' sexual swelling cycles. Nevertheless, the data presented imply that leverage could have played an important role in the relationship between Dzeeta and Desmond.

The above example based upon the work of Vervaecke et al. (1999) demonstrates the utility of the power framework. It embraces the problem that matrices based upon different behaviors produce different hierarchies (see van Hooff and Wensing 1987). It also allows researchers to go beyond general statements concerning the power of one individual relative to another; the components of that power can be identified and singled out for further analysis. Additionally, power structures can be more accurately described and compared across dyads, classes, groups, and species.

The utility of applying the framework of power is also exemplified with the research of Thompson (1960a,b), who conducted behavioral observations on wild and captive house finches (Carpodacus mexicanus). Table 2 is a matrix from this study and is based upon the ability to make an opponent retreat. Interactions that caused the subordinate individuals to retreat (scope) were called "hostile encounters" by Thompson (1960b), and thus the means of power can potentially be interpreted as aggression. Unlike the bonobo study, this matrix is not limited to the feeding context. Female RB has an $11 \%$ probability of evoking a retreat (scope) from male $\mathrm{R}$ with aggression (means), but $100 \%$ probability of evoking a retreat from male WW with aggression. In other words, RB is not as successful as the bonobo Dzeeta (discussed in the previous example) at using aggression to evoke certain 
TABLE 2

Frequencies of wins in mixed groups of caged male and female house finches from November 14 to December 17, 1954

\begin{tabular}{|c|c|c|c|c|c|c|c|c|c|c|}
\hline \multirow[t]{2}{*}{ Winners } & \multirow[t]{2}{*}{ Sex } & \multicolumn{9}{|c|}{ Loser } \\
\hline & & RB & WB & $\mathbf{R}_{\mathbf{F}}$ & WR & $\mathbf{R}_{\mathbf{M}}$ & $\mathbf{W}$ & WW & BB & B \\
\hline $\mathbf{R B}$ & $\mathrm{F}$ & - & 7 & 14 & 12 & 2 & 1 & 9 & 6 & 6 \\
\hline WB & $\mathrm{F}$ & & - & 19 & 39 & 20 & 0 & 34 & 23 & 34 \\
\hline $\mathbf{R}_{\mathbf{F}}$ & $\mathrm{F}$ & & & - & 28 & 28 & 23 & 23 & 21 & 18 \\
\hline WR & $\mathrm{F}$ & & 1 & & - & 42 & 2 & 47 & 1 & 39 \\
\hline $\mathbf{R}_{\mathrm{M}}$ & M & 16 & 1 & 1 & 1 & - & 24 & 62 & 26 & 62 \\
\hline $\mathbf{W}$ & M & & 29 & & 20 & & - & 21 & 15 & 16 \\
\hline WW & M & & & 1 & & & 2 & - & 26 & 60 \\
\hline BB & M & & 1 & 2 & 33 & 1 & 1 & 2 & - & 60 \\
\hline B & M & & & 1 & & & 6 & & & - \\
\hline
\end{tabular}

$\mathrm{F}=$ female; $\mathrm{M}=$ male. A "win" is defined by the ability to make an opponent retreat in a hostile encounter.

The above table is taken from Thompson (1960b).

types of submission in males. Of course, the data used to determine Dzeeta's power was limited to the feeding context, and she may not have the same amount of power outside of this.

The finch study also illustrates the utility of breaking down power into its different bases. Female RB had only one leg when she was captured, and while she had the power to make other birds retreat at the beginning of the study (the matrix presented in Table 2 represents this time period), she quickly tired and was at a disadvantage when encounters required force (Thompson 1960b). This asymmetry in fighting ability became apparent and the scope of her power gradually diminished. Her weight may have been greater at the beginning of the study, but several months after the initial hierarchy (presented in Table 2) was developed, she had dropped to the lowest rank in the hierarchy and was the lowest in weight. Without the data on initial weights, the base of RB's power cannot be conclusively established. Hence, collecting body weight and condition data throughout the entire study is crucial to truly understanding the power dynamics of a dyad.

Nonetheless, Thompson (1960a,b) found that power in intersexual dyads varied across the year (Figure 3). A hierarchy based on agonistic encounters will vary in this species depending upon which months the finches were observed. Females are more powerful when they are without young and being

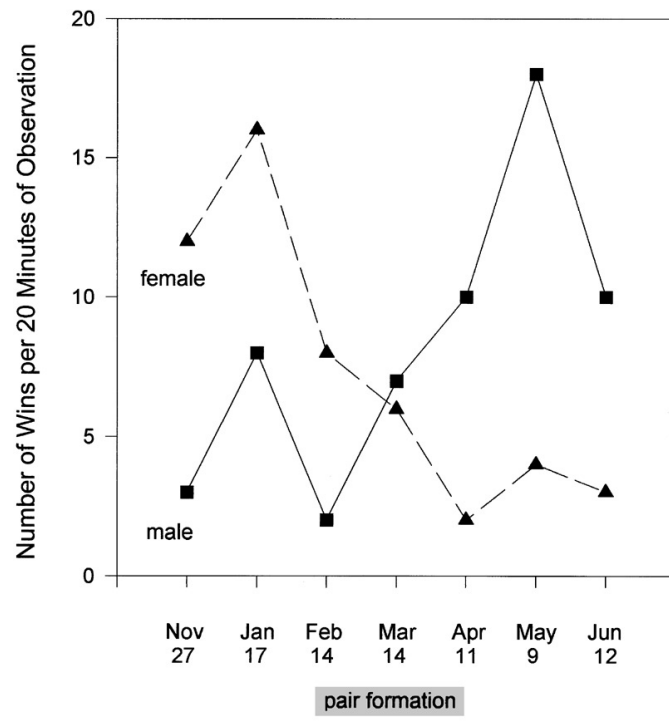

incubation \& young

Figure 3. OUtcomes of Intersexual agonistic Encounters in House Finches.

Intersexual aggressiveness of caged male and female house finches in 1954-55, the period of the study corresponding to the hierarchy presented in Table 2, after Thompson (1960b).

courted, but in the spring and early summer, when they form pairs and rear their young, the males become more powerful (cf. Thompson 1960a,b). If male and female fighting abilities vary seasonally, then males can be said to become dominant during this brief period. A more likely explanation, however, is that a dif- 
ferent asymmetry in the dyad changes: females rely on males to help feed them during the period of incubation and to help feed the young after they hatch (Thompson 1960a). When males depend upon females for mating opportunities, females have leverage. Once females can no longer offer mating opportunities and depend upon male services, males have leverage (see also gibbons: Reichard 1995:89). Thus, weight may not be the best determinant of power in intersexual dyads in this species.

The bonobos in the Vervaecke et al. (1999) experiments were studied in pair tests where service economies, and hence leverage, may not always become apparent. Nevertheless, leverage, possibly based upon sexual status of the female, may have played an important role in this study. Leverage also probably explains the variation in male-female relationships in the finch study. Unfortunately, the data that are most lacking from previous studies are descriptions of the social economy in order to examine leverage. This gap leaves important questions unanswered. For example, is the sex ratio in the neighborhood (all individuals/groups that have "repeated acquaintance": cf. Jolly 1966:148; Richard 1978:166) male-biased or femalebiased? The supply and demand of males and females may influence power relationships (cf. Noë et al. 1991). What are the reproductive states of all relevant individuals? Do certain individuals have special skills or resources that can be exchanged or interchanged? Hemelrijk's (1990) interchange matrices may help isolate relationships affected by leverage.

One note of caution is necessary, however. Researchers must be careful in assessing what behaviors or resources are being exchanged during interchange. For example, Hemelrijk and colleagues (1992) found that male chimpanzees more often groomed estrous females with whom they mated more frequently; thus they suggested that this result may reflect a sexual exchange between males and estrous females. In a later paper (Hemelrijk et al. 1999), however, they found that the male chimpanzees who groomed estrous females with whom they had mated more often did not sire more offspring with those females; thus they then suggested that trade did not occur. While paternity is the ultimate goal of a male trading with an estrous female, it is not necessarily what the female offers for exchange. Female chimpanzees can only offer mating opportunities to males. They can influence the likelihood of paternity with the timing of this exchange, but they cannot, to my knowledge, control the paternity of their offspring unless they only mate with one male. Females can only trade those resources over which they have control, which in this case is mating opportunities.

Researchers have already been measuring much of the pertinent information to analyze power. The problem with the traditional dominance concept has not been the existence of competing methods for measuring and analyzing dominance. Rather, most of the difficulties associated with the traditional dominance concept are the result of a theoretical framework too narrow to encompass all aspects of power.

\section{Relationship Between Dominance AND LEVERAGE}

The above examples highlight the fact that the relationship of dominance and leverage is unclear. It would be useful if power were a linear combination of dominance and leverage. Unfortunately, the exact nature of the relationship is difficult to determine without more empirical observations. At a basic level, power $(P)$ can be thought of as a function of dominance $(D)$ and leverage $(L)$,

$$
P=\mathrm{f}(D, L)
$$

where power refers to the ability of $A$ to make $B$ do something based upon an asymmetry, and dominance and leverage refer to the basis for this power. The following descriptions of the above function are assumed to be true:

As dominance increases, power increases $(\Delta P / \Delta D \geq 0)$.

As leverage increases, power increases $(\Delta P / \Delta L \geq 0)$.

The more dominance an individual has, the less additional power an individual gains by adding more dominance $\left(\Delta^{2} P / \Delta \mathrm{D}^{2}<0\right)$. 
The more leverage an individual has, the less additional power an individual gains by adding more leverage $\left(\Delta^{2} P / \Delta L^{2}<0\right)$.

The effect of leverage on power may depend upon how much dominance an individual may have and vice versa $\left(\Delta^{2} P / \Delta D \Delta L=\right.$ ???).

Additional research is needed to determine how dominance and leverage interact. I suspect that extreme dominance negates leverage at any level. In a species that is highly sexually dimorphic in body size, the smaller sex has very few options for leverage: most resources can be taken by force by the larger sex. For example, northern elephant seal (Mirounga angustirostris) sex ratios at rookeries range from 20-100:1 to 1:3 across the mating season (Le Boeuf and Reiter 1988). Despite the variation in sex ratios, the females probably do not enjoy an increase in leverage in intersexual dyads because of sexual dimorphism (males are 3-4 times heavier and 1.4 times longer than females; Deutsch et al. 1994). Perhaps the only sources of leverage in these types of species are skill and knowledge. Nevertheless, force can still be used to coerce a smaller, knowledgeable individual into giving up that information (e.g., torture in humans). Hence, leverage may simply not be relevant in this case. When dominance is not so extreme, the interaction between leverage and dominance is not as clear. For instance, female Western gulls (Larus occidentalis) are 20-25\% smaller than males and yet have essentially egalitarian intersexual relationships (Pierotti et al. 1997). Leverage is likely to play a role in these relationships. More research is clearly needed to elucidate the relationship between dominance and leverage.

\section{Conclusions}

The dominance concept as it is currently defined has deficiencies. As a result, a body of literature has developed that is confusing and contradictory. The "tight logical theory" that Bernstein (1976) professed to exist has been repeatedly called into question. Hand (1986), Noë et al. (1980, 1991), Noë and Hammerstein $(1994,1995)$, and others have made significant advancements in the study of power in animal behavior. No previous study has recognized that leverage and dominance are fundamentally different, however. Rather than modifying the dominance concept within the current framework, dominance is more appropriately considered within the greater context of power. When this approach is taken, much of the present confusion associated with dominance is resolved. Furthermore, the broader framework of power embraces many other currently accepted ideas about social relations, creating the possibility for more integrated theories. Many researchers have demonstrated the existence of leverage without necessarily expressing it as their intention. Thus, while additional research is needed that explicitly tests for the effects of leverage, the crucial issue to address now is how dominance and leverage interact to create the overall power dynamic within a dyad.

\section{ACKNOWLEDGMENTS}

I would especially like to thank C van Schaik for our numerous discussions that helped me to clarify my thoughts about power and for his unlimited enthusiasm and encouragement. E C Kirk provided invaluable emotional and logistical support as well as helpful comments on the manuscript. I am also grateful to D Brockman, K Dausmann, L Digby, K Glander, M Munger, C Nunn, D Overdorff, and K Smith for their discussions on this topic as well as comments on the manuscript. This research also benefited from comments at an informal talk given at the department of Biological Anthropology and Anatomy at Duke University, from discussions with Signe Preuschoft, Jessica Flack, and Frans de Waal, and from comments by two anonymous reviewers. This research was supported by a NSF Graduate Student Fellowship.

\section{REFERENCES}

Barkow J H. 1975. Prestige and culture: biosocial interpretation. Current Anthropology 16(4):553-572.

Bartos L, Perner V. 1998. Distribution of mating across season and reproductive success according to dominance in male red deer. Folia Zoologica 47(1):7-12.
Berard J. 1999. A four-year study of the association between male dominance rank, residency status, and reproductive activity in rhesus macaques $(\mathrm{Ma}$ caca mulatta). Primates 40(1):159-175.

Bergstrom C T, Real L A. 2000. Towards a theory of 
mutual mate choice: lessons from two-sided matching. Evolutionary Ecology Research 2:493-508.

Bernstein I S. 1976. Dominance, aggression and reproduction in primate societies. Journal of Theoretical Biology 60:459-472.

Bernstein I S. 1981. Dominance: the baby and the bathwater. Behavioral and Brain Sciences 4:419-429.

Brown J L. 1963. Aggressiveness, dominance, and social organization in the Stellar's jay. Condor 65:460484.

Carpenter C R. 1942. Sexual behavior of free-ranging rhesus monkeys (Macaca mulatta). I. Specimens, procedures and behavioral characteristics of estrus. Journal of Comparative Psychology 33:113-142.

Chapais B. 1991. Primates and the origins of aggression, power, and politics among humans. Pages 190-218 in Understanding Behavior: What Primate Studies Tell Us About Human Behavior, edited by J D Loy and C B Peters. Oxford: Oxford University Press.

Chapais B. 1992. The role of alliance in social inheritance of rank among female primates. Pages 2959 in Coalitions and Alliances in Humans and Other Animals, edited by A H Harcourt and F B M de Waal. Oxford: Oxford University Press.

Cook K S, Emerson R M. 1978. Power, equity, and commitment in exchange networks. American Sociological Review 43:721-739.

Cook K S, Emerson R A, Gillmore M R, Yamagishi T. 1983. The distribution of power in exchange networks: theory and experimental results. American Journal of Sociology 89(2):275-305.

Dahl R A. 1957. The concept of power. Behavioural Science 2:201-215.

Datta S B. 1983. Relative power and the maintenance of dominance. Pages 103-112 in Primate Social Relationships: An Integrated Approach, edited by $\mathrm{R} \mathrm{A}$ Hinde. Oxford: Blackwell Science.

Datta S B. 1989. Demographic influences on dominance structure among female primates. Pages 265-284 in Comparative Socioecology: Behavioural Ecology of Humans and Other Mammals, edited by V Standen and R A Foley. Oxford: Blackwell Science.

de Ruiter J R, van Hooff J A R A M. 1993. Male dominance rank and reproductive success in primate groups. Primates 34:513-523.

Deutsch C J, Crocker D E, Costa D P, Le Boeuf B J. 1994. Sex- and age-related variation in reproductive effort of northern elephant seals. Pages 169210 in Elephant Seals: Population Ecology, Behavior, and Physiology, edited by B Le Boeuf and R M Laws. Berkeley (CA): University of California Press.

de Waal F B M. 1982. Chimpanzee Politics: Power and Sex among Apes. Baltimore (MD): The Johns Hopkins University.

de Waal F B M. 1986. The integration of dominance and social bonding in primates. Quarterly Review of Biology 61:459-479.

de Waal F B M. 1989. Dominance 'style' and primate social organization. Pages 243-263 in Comparative Socioecology: The Behavioural Ecology of Humans and Other Mammals, edited by V Standen and R A Foley. Oxford: Blackwell Science.

de Waal F B M. 1996. Conflict as negotiation. Pages 159-172 in Great Ape Societies, edited by W C McGrew et al. Cambridge: Cambridge University Press.

Dewsbury D A. 1981. Social dominance, copulatory behaviour and differential reproduction in deer mice (Peromyscus maniculatus). Journal of Comparative and Physiological Psychology 95(6):880-895.

Dewsbury D A. 1990. Fathers and sons: genetic factors and social dominance in deer mice, Peromyscus maniculatus. Animal Behaviour 39:284-289.

Drews C. 1993. The concept and definition of dominance in animal behaviour. Behaviour 125:283-313.

Dugatkin L A, Ohlsen S R. 1990. Contrasting asymmetries in value expectation and resource holding power: effects on attack behaviour and dominance in pumpkinseed sunfish, Lepomis gibbosus. Animal Behaviour 39 (4):802-804.

Emerson R M. 1962. Power-dependence relations. American Sociological Review 27:31-40.

Emlen S T, Oring L W. 1977. Ecology, sexual selection, and the evolution of mating systems. Science 197:215-223.

Fedigan L M. 1983. Dominance and reproductive success in primates. Yearbook of Physical Anthropology 26:91-129.

Francis R C. 1988. On the relationship between aggression and social dominance. Ethology 78:223237.

Frank L G. 1986. Social organization of the spotted hyaena Crocuta crocuta. II. Dominance and reproduction. Animal Behaviour 34:1510-1527.

Gowaty P A. 1997. Sexual dialectics, sexual selection, and variation in reproductive behavior. Pages 351384 in Feminism and Evolutionary Biology: Boundaries, Intersections, and Frontiers, edited by P A Gowaty. New York: Chapman \& Hall.

Hall K R L, DeVore I. 1965. Baboon social behavior. Pages 53-110 in Primate Behavior, edited by I DeVore. New York: Holt.

Hamilton III W J, McNutt J W. 1997. Determinants of conflict outcomes. Pages 179-224 in Perspectives in Ethology, Volume 12, edited by D H Owings et al. New York: Plenum Press.

Hand J L. 1986. Resolution of social conflicts: dominance, egalitarianism, spheres of dominance, and game theory. Quarterly Review of Biology 61:201-220.

Hemelrijk C K. 1990. Models of, and tests for, reciprocity, unidirectionality and other social interac- 
tion patterns at a group level. Animal Behaviour 39:1013-1029.

Hemelrijk C K, Meier C, Martin R D. 1999. 'Friendship' for fitness in chimpanzees? Animal Behaviour 58:1223-1229.

Hemelrijk C K, van Laere G J, van Hooff J A R A M. 1992. Sexual exchange relation ships in captive chimpanzees? Behavioral Ecology and Sociobiology 30:269-275.

Hinde R A, Stevenson-Hinde J. 1976. Towards understanding relationships: dynamic stability. Pages 451-479 in Growing Points in Ethology, edited by P P G Bateson and R A Hinde. Cambridge: Cambridge University Press.

Holekamp K E, Smale L, Szykman M. 1997. Rank and reproduction in the female spotted hyena. Journal of Reproductive Fertility 108(2):229-237.

Huck U W, Lisk R D, McKay M V. 1988. Social dominance and reproductive success in pregnant and lactating golden hamsters (Mesocricetus auratus) under seminatural conditions. Physiology and $\mathrm{B} e$ haviour 44(3):313-320.

Inoue M, Mitsunaga F, Nozaki M, Ohsawa H, Takenaka A, Sugiyama Y, Shimizu K, Takenaka O. 1993. Male dominance rank and reproductive success in an enclosed group of Japanese macaques: with special reference to post-conception mating. Primates 34:503-511.

Jenks S M, Weldele M L, Frank L G, Glickman S E. 1995. Acquisition of matrilineal rank in captive spotted hyaenas: emergence of a natural social system in peer-reared animals and their offspring. Animal Behaviour 50:893-904.

Jolly A. 1966. Lemur Behavior: A Madagascar Field Study. Chicago (IL): University of Chicago Press.

Jolly A. 1984. The puzzle of female feeding priority. Pages 197-215 in Female Primates: Studies by Women Primatologists, edited by M Small. New York: Alan R Liss.

Jones C B. 2000. Alouatta palliata politics: empirical and theoretical aspects of power. Primate Reports 56:3-21.

Johnsson J I. 1993. Big and brave: size selection affects foraging under risk of predation in juvenile rainbow trout, Oncorhynchus mykiss. Animal Behaviour 45:1219-1225.

Lambert D M, Millar C D, Jack K, Anderson S, Craig J L. 1994. Single- and multilocus DNA fingerprinting of communally breeding pukeko: do copulations or dominance ensure reproductive success? Proceedings of the National Academy of Sciences of the United States of America 91 (20):9641-9645.

Le Boeuf B J, Reiter J. 1988. Lifetime reproductive success in northern elephant seals. Pages 344-362 in Reproductive Success: Studies of Individual Variation in Contrasting Breeding Systems, edited by T H CluttonBrock. Chicago (IL): University of Chicago Press.
Lemel J, Wallin K. 1993. Status signaling, motivational condition and dominance: an experimental study in the great tit, Parus major, L. Animal Behaviour 45:549-558.

Maestripieri D. 1996. Primate cognition and the bared-teeth display: a reevaluation of the concept of formal dominance. Journal of Comparative Psychology 110(4):402-405.

Maslow A H. 1940. Dominance-quality and social behaviour in infra-human primates. Journal of Social Psychology 11:313-324.

Maynard Smith J, Parker G A. 1976. The logic of asymmetric contests. Animal Behaviour 24:159-175.

Noë R. 1990. A veto game played by baboons: a challenge to the use of the prisoner's dilemma as a paradigm for reciprocity and co-operation. Animal Behaviour 39:78-90.

Noë R. 1992. Alliance formation among male baboons: shopping for profitable partners. Pages 285-321 in Coalitions and Alliances in Humans and Other Animals, edited by A H Harcourt and F B M de Waal. Oxford: Oxford University Press.

Noë R, Hammerstein P. 1994. Biological markets: supply and demand determine the effect of partner choice in cooperation, mutualism and mating. $\mathrm{Be}$ havioral Ecology and Sociobiology 35:1-11.

Noë R, Hammerstein P. 1995. Biological markets. Trends in Ecology E Evolution 10:336-339.

Noë R, de Waal F B M, van Hooff J A R A M. 1980. Types of dominance in a chimpanzee colony. Folia Primatologica 24:90-110.

Noë R, van Schaik C P, van Hooff J A R A M. 1991. The market effect: an explanation for pay-off asymmetries among collaborating animals. Ethol ogy 87:97-118.

Nunn C L, Lewis R J. 2001. Co-operation and collective action in animal behaviour. Pages 42-67 in Economics in Nature, edited by R Noë et al. Cambridge: Cambridge University Press.

Oberski I M, Wilson J D. 1991. Territoriality and sitedependent dominance: on two related concepts in avian social organization. Ethology 87:225-236.

Owens D, Owens M. 1996. Social dominance and reproductive patterns in brown hyaenas, Hyaena brunnea, of the central Kalahari desert. Animal Behaviour 51:535-551.

Packer C, Pusey A. 1985. Asymmetric contests in social mammals: respect, manipulation and age-specific aspects. Pages 173-186 in Evolution: Essays in Honour of John Maynard Smith, edited by P J Greenwood et al. Cambridge: Cambridge University Press.

Pereira M E, Kaufman R, Kappeler P M, Overdorff D J. 1990. Female dominance does not characterize all of the Lemuridae. Folia Primatologica 55:96-103.

Pierotti R, Annett C A, Hand J L. 1997. Male and female perceptions of pair-bond dynamics: monogamy in western gulls Larus occidentalis. Pages 261- 
275 in Feminism and Evolutionary Biology: Boundaries, Intersections, and Frontiers, edited by P A Gowaty. New York: Chapman \& Hall.

Piper W H. 1997. Social dominance in birds. Pages 125-187 in Current Ornithology, edited by J V Nolan. New York: Plenum Press.

Poole J H. 1989. Announcing intent: the aggressive state of musth in African elephants. Animal Behaviour 37:140-152.

Popp J L, De Vore I. 1979. Aggressive competition and social dominance theory: synopsis. Pages 317-338 in The Great Apes, edited by D A Hamburg and $\mathrm{E} \mathrm{R}$ McCown. Menlo Park (CA): Benjamin/Cummings.

Preuschoft S. 1999. Are primates behaviorists?: formal dominance, cognition, and free-floating rationales. Journal of Comparative Psychology 113(1):91-95.

Preuschoft S, van Schaik C P. 2000. Dominance and communication: conflict management in various social settings. Pages 77-105 in Natural Conflict Resolution, edited by F Aureli and F B M de Waal. Berkeley (CA): University of California Press.

Pusey A, Williams J, Goodall J. 1997. The influence of dominance rank on the reproductive success of female chimpanzees. Science 277:828-831.

Reichard U. 1995. Sozial- und Fortpflanzungsverhalten von Weißhandgibbons (Hylobates lar): Eine Freilandstudie im thailändischen Khao Yai Regenwald. [PhD dissertation]. Göttingen (Germany): Universität Göttingen.

Richard A F. 1978. Behavioral Variation: Case Study of a Malagasy Lemur. Lewisburg (PA): Bucknell University.

Roeder J J, Fornasieri I. 1995. Does agonistic dominance imply feeding priority in lemurs-a study in Eulemur fulvus mayottensis. International Journal of Primatology 16(4):629-642.

Rowell T. 1974. The concept of social dominance. Behavioral Biology 11:131-154.

Schartl M, Erbelding D C, Holter S, Nanda I, Schmid M, Schroeder J H, Epplen J T. 1993. Reproductive failure of dominant males in the poeciliid fish Lima perugiae determined by DNA fingerprinting. Proceedings of the National Academy of Sciences of the United States of America 90(15):7064-7068.

Schjelderup-Ebbe T. 1922. Beiträge zur Sozialpsychologie des Haushuhns. Zeitschrift für Psychologie 88:225-252.

Simon H A. 1953. Notes on the observation and measurement of political power. Journal of Politics 15:500-516.
Smuts B B. 1985. Sex and Friendship in Baboons. Hawthorne (NY): Aldine.

Smuts B B. 1987. Gender, aggression, and influence. Pages 400-412 in Primate Societies, edited by B B Smuts et al. Chicago (IL): University of Chicago Press.

Stammbach E. 1988. Group responses to specially skilled individuals in a Macaca fascicularis group. Behaviour 107:241-266.

Takahata Y, Huffman M A, Suzuki S, Koyama N, Yamagiwa J. 1999. Why dominants do not consistently attain high mating and reproductive success: a review of longitudinal Japanese macaque studies. Primates 40(1):143-158.

Terrill S B. 1987. Social dominance and migratory restlessness in the dark-eyed junco (Junco hyemalis). Behavioral Ecology and Sociobiology 21:1-11.

Thompson W L. 1960a. Agonistic behaviour in the house finch. Part I. Annual cycle and display patterns. Condor 62:245-271.

Thompson W L. 1960b. Agonistic behaviour in the house finch. Part II. Factors in aggressiveness and sociality. Condor 62:378-402.

van Hooff J A R A M, Wensing J A B. 1987. Dominance and its behavioral measures in a captive wolf pack. Pages 219-252 in Man and Wolf, edited by H Frank. Dordrecht: Junk Publishers.

van Noordwijk M A, van Schaik C P. 1999. The effects of dominance rank and group size on female lifetime reproductive success in wild long-tailed macaques, Macaca fascicularis. Primates 40:105-130.

Verbeek M E M, de Goede P, Drent P J, Wiepkema P R. 1999. Individual behavioural characteristics and dominance in aviary groups of great tits. $B e-$ haviour 136:23-48.

Vervaecke H, de Vries H, van Elsacker L. 1999. An experimental evaluation of the consistency of competitive ability and agonistic dominance in different social contexts in captive bonobos. Behaviour 136:423-442.

Vervaecke H, de Vries H, van Elsacker L. 2000. Dominance and its behavioral measures in a captive group of bonobos (Pan paniscus). InternationalJournal of Primatology 21(1):47-68.

Vestergaard K S, Kruijt J P, Hogan J A. 1993. Feather pecking and chronic fear in groups of red junglefowl: their relations to dustbathing, rearing environment and social status. Animal Behaviour 45:11271140.

Yasukawa K, Bick E I. 1983. Dominance hierarchies in dark-eyed juncos (Junco hyemalis): a test of a game theory model. Animal Behaviour 31:439-448. 